\title{
Explorando alguns temas relacionados à sexualidade junto aos Wajãpi do Amapari (AP)
}

\author{
L Juliana Rosalen \\ Universidade de São Paulo, São Paulo, São Paulo, Brasil
}

DOI 10.11606/issn.2316-9133.v24i24p524-537

resumo Este artigo pretende explorar teorias e práticas wajápi relacionadas à sexualidade. Serão desenvolvidas aqui duas dimensôes específicas: a iniciação sexual de jovens mulheres e as relaçóes extraconjugais. Ambos os temas são fundamentais para a compreensão das sexualidades wajápi e contribuem para desconstrução de preconceitos proferidos pelos karai kõ (não índios). As relaçôes sexuais, além de suprirem os desejos, permitem colocar em movimento um princípio maior, que diz respeito à própria dimensão sociopolítica: a disseminação de substâncias via afinização e predação.

palavras-chave Etnologia; Sexualidade; Substâncias; Afinização; Predação.

Exploring some themes related to sexuality among the Wajápi from Amapari (AP)

abstract This article aims to explore Wajápi theories and practices related to sexuality. Two specific dimensions will be developed here: the sexual initiation of young women and extramarital relations. Both issues are key to understanding the Wajápi sexualities and contribute to the deconstruction of prejudices cast by the karai kó (non-indians). Sexual relations, beyond fulfilling desires, allow to put in motion a major principle related to the socio-political dimension of the group: the spread of substances through affinization and predation.

keywords Ethnology; Sexuality; Substance; Affinization; Predation. 


\section{Explorando alguns temas relacionados à sexualidade junto aos Wajãpi do Amapari (AP)}

Neste texto, pretendo discutir algumas dimensóes relacionadas à questáo da sexualidade junto aos Wajápi, a partir de dados etnográficos obtidos em minha pesquisa de mestrado. ${ }^{1}$

De tema subsidiário, a sexualidade passou a ocupar um lugar fundamental na pesquisa, me permitindo redimensionar a discussáo sobre as DST (Doenças Sexualmente Transmissíveis) junto aos Wajāpi. Era necessário compreender teorias e práticas relacionadas às sexualidades wajāpi de forma a refutar, com densos subsídios, os preconceitos e estereótipos disseminados pelos não índios acerca de uma suposta e genérica sexualidade indígena, que infestavam as açóes de prevenção das DST e AIDS.

Ao me preparar para a pesquisa de campo, percebi que a temática da sexualidade estava presente em muitas etnografias, porém de forma pulverizada. Eram, de fato, poucos os trabalhos que se dedicavam sistematicamente a essa discussão. ${ }^{2}$ Presumi inicialmente que a dificuldade em desenvolver pesquisas sobre essa temática fosse uma especificidade de nossa sociedade, devido aos tabus e às moralidades existentes. Mas percebi, no decorrer da pesquisa, que também para os Wajápi se tratava de um tema bastante delicado e que, portanto, exigia extremo cuidado e discrição tanto no decorrer da pesquisa quanto em sua divulgaçáo.

Em minha dissertação, desenvolvi um capítulo dedicado apenas a essa temática, realizando um recorte específico no complexo e denso universo de elaboraçóes e práticas wajāpi a esse respeito. Neste artigo, me proponho a discutir duas dimensóes lá apresentadas: a iniciação sexual de jovens mulheres e a questão das relaçóes extraconjugais.

A escolha dessas dimensóes não foi ocasional. Além da relevância acadêmica, ou seja, da importância desses temas para a compreensáo das teorias e práticas de outros povos acerca da sexualidade, havia uma preocupaçáo em focar assuntos que são alvos frequentes de preconceito por parte dos profissionais, especialmente de saúde, que atuam junto aos Wajāpi.

Não é raro escutar profissionais falando em "abuso sexual" de crianças ou de moças que foram iniciadas sexualmente. Ou entáo, durante campanhas, relacionadas à prevenção das DST e AIDS, ouvir que "os Wajãpi são promíscuos", "namoram com todo mundo", como se vivessem em uma sociedade amoral (sem regras, já que considerados "primitivos", como explicitam alguns profissionais) ou mesmo imoral (quando o movimento é justamente inseri-los na identidade nacional e na moralidade católica hegemônica). Antes de adentrar nas reflexóes acerca dessas duas dimensões propriamente ditas, vale apontar algumas reflexões mais gerais sobre 
a questão da sexualidade, depreendidas a partir das análises dos dados de campo.

\section{Aproximações à temática}

Ao longo da pesquisa, fui percebendo que há dois pilares constitutivos das sexualidades nos mundos wajāpi: as relaçóes conjugais e as relaçóes extraconjugais. E esses pilares, longe de produzir engessamentos, possibilitam justamente uma abertura para novas experiências, delimitando somente um limiar relativo às intensidades de perigos e às possibilidades ou não de suas neutralizaçóes. Das relaçóes sexuais enquanto mantenedoras de grupos de substância, e de sua potencialidade criadora junto aos amó kó (membros de outros grupos locais wajāpi), às relaçóes com categorias de alteridade mais distantes, porém extremamente sedutoras, existe uma constante: as trocas são desejadas e irresistíveis para os Wajāpi. ${ }^{3}$ Como eles mesmos gostam de enfatizar: nós não vamos deixar de namorar. ${ }^{4}$ Apesar dessa fala fazer referência especialmente a um lugar onde ocorrem intensas trocas sexuais, que é a Casa de Saúde Indígena (CASAI), em Macapá, pode ser estendida também à Terra Indígena e outras cidades onde circulam os Wajápi.

As percepçóes a respeito da sexualidade variam especialmente de acordo com a formação e as experiências vivenciadas por cada interlocutor. Há diferenças sensíveis entre as falas de jovens ou pessoas mais velhas, mulheres e homens, ${ }^{5}$ assalariados - professor, agente de saúde, agente de saneamento, aposentado, funcionário da FUNAI - e não assalariados, e também diferença nas falas de variadas famílias e de acordo com o grupo político de pertença. Atualmente, poderíamos incrementar a discussão incorporando os jovens que migram para as cidades para estudar. Vivendo e frequentando escolas nas periferias de Macapá, esses jovens têm um acesso intenso a outras referências relacionadas à sexualidade ${ }^{6}$ que não são as mesmas, acessadas por assalariados quando estes vêm à cidade para fazer compras ou resolver problemas pessoais.

Nos depoimentos que pretendo apresentar, muitas vezes estas diferenciações são patentes. As pessoas mais velhas, em geral, possuem discursos mais conservadores em relaçáo às mudanças de comportamento dos jovens, incluindo uma forte crítica à precocidade das relaçóes sexuais. ${ }^{7}$ Os mais jovens, por sua vez, com a experimentação de tecnologias dos não índios (karai kō), tendem a positivar essas mudanças. A diferença de gênero é mais perceptível nas conversas sobre iniciação sexual e menos perceptível nas falas acerca das relaçóes extraconjugais. Quanto a esse aspecto, faço um rápido parêntese: ao reler o material de minha dissertaçáo, me dei conta de que eu havia me preocupado em compreender como ocorria o processo 
de iniciação sexual das jovens, tanto pelo viés feminino, quanto pelo viés masculino, mas não tive a mesma preocupação em entender como ocorria a iniciação sexual masculina.

Hoje, retroativamente, consigo perceber o quanto de opção e o quanto de acaso houve nessa escolha. A opção deu-se pela facilidade de interlocuções com as mulheres, a partir da relação de confiança e intimidade construída no decorrer de anos de trabalho junto aos Wajápi. E o acaso, por ter vivenciado uma situaçáo bastante tensa, na qual a equipe de saúde queria denunciar como abuso sexual de menor a iniciaçáo sexual de uma jovem, encontrada pela equipe na estrada, quando retornava para a sua casa. $\mathrm{O}$ resultado dessa escolha é apresentado a seguir, tendo clareza de que essa discussão necessitaria de um contraponto a ser fornecido pela descrição da iniciação sexual masculina.

Por fim, vale um último comentário acerca da diferença entre os discursos produzidos pelos membros de diferentes grupos políticos wajāpi. Essas diferenças, na prática, são muito sutis, porém os grupos fazem do locus da sexualidade mais um espaço para a continuidade da guerra de acusaçóes, seja em relação à forma de iniciar sexualmente uma menina, seja em relação aos namoros extraconjugais.

\section{Iniciação sexual}

As incursōes na sexualidade, entre os Wajápi, são vistas com naturalidade e em geral acontecem desde a infância, com as primeiras manipulaçóes dos órgãos sexuais enquanto fonte de divertimento e prazer. Nesse sentido há muito pouca diferença com o que ocorre entre os não índios, com exceção de que, na nossa sociedade, as famílias reagem de forma mais ou menos repressora, procurando ocultar ou coibir essas experimentaçóes.

Como muitos Wajápi gostam de frisar, essas brincadeiras não são consideradas "namoros", termo utilizado como sinônimo para as relaçóes sexuais (-poreno). Elas apenas váo preparando os corpos para a entrada no mundo adulto. A imitação das relaçôes sexuais contribui para "amolecer", "abrir" e "furar" a vagina, que é o lugar por onde escorrerá o primeiro sangue e cairão futuramente as crianças.

A iniciação sexual, que é a consumação da relaçăo sexual propriamente dita, ocorre somente após determinadas mudanças corporais características, tais como o aparecimento de seios, pelos e menstruação nas meninas, e mudança de voz e início da produção de esperma com relaçáo aos me-

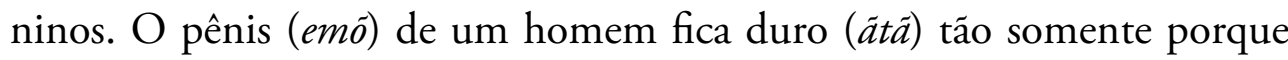
este possui sêmen $\left(t a^{\prime} y\right)$. A iniciaçáo sexual das meninas diz respeito exclusivamente ao universo feminino, pelo menos para as famílias com as 
quais fiz pesquisa. Quando esse assunto, por descuido, é compartilhado com os homens, provoca um grande sentimento de vergonha $(-s i)$. E, se em determinados contextos a vergonha é profilática, em outros, quando exacerbada, pode trazer um enfraquecimento da pessoa através da saída do princípio vital (-'ā) de seu corpo (GALLOIS, 1988, p. 215).

A primeira relação sexual de uma menina, de acordo com os meus interlocutores, pode se suceder de duas maneiras: fora ou dentro de um arranjo de casamento. Quando fora de um arranjo de casamento, ocorre geralmente durante os caxiris. ${ }^{8} \mathrm{~A}$ relação é feita até aparecer o sangue, sinal de que a vagina da menina foi furada. Esse primeiro sangue, segundo meus interlocutores, recebe uma denominação específica okaoka, diferindo-se de $-w y$ (que é utilizado para falar do sangue de forma mais genérica) e de ute (utilizado para designar o sangue menstrual). A quantidade de sangue varia, mas a lógica que subjaz à iniciação é a mesma da menstruação: o sangue, assim como o suor e calor da relaçáo, promove perda do princípio vital, sendo necessária a entrada da menina em um processo de reclusão $(-k o a k o)$.

Gallois aponta que o resguardo deve ser visto para além de um comportamento de evitação de malefícios, "sobretudo como uma atitude positiva, mantenedora das substâncias vitais. [...] Assim, -koako remete ao conhecimento, à atençáo, à consciência, isto é, à existência propriamente dita" (1988, p. 196). Durante esse resguardo, será apenas a mãe quem vai cuidar da menina-moça, preparando "remédios", aplicando-os cuidadosamente e aconselhando suas filhas. O tempo da reclusão pode variar e depende da recuperaçáo, esta entendida em um amplo sentido, da menina-moça.

Quando a iniciação sexual ocorre dentro de um arranjo de casamento, as sogras intercedem junto aos genros, aconselhando-os sobre como iniciar suas futuras esposas. Porém, dentro ou fora de arranjos de casamento, as meninas-moças possuem certo receio quanto à iniciação, ${ }^{9}$ receio esse que tende a se dissipar a partir da aplicação de remédios do mato ${ }^{10} \mathrm{e}$ também com a prática. A noçáo de acostumar-se (-jipokua) é intimamente relacionada à elaboração de sentimentos. A vida sexual se forja cotidianamente e junto aos parceiros.

$\mathrm{Na}$ perspectiva dos homens, há duas maneiras possíveis de se consumar a iniciação feminina: com ou sem o consentimento da menina-moça. Ambas as formas são aceitas e consideradas legítimas pelos Wajápi. Os homens reforçam que são marcadores corporais, especialmente a beleza, que tornam as meninas-moças atraentes, irresistíveis para eles. Os seios, juntamente com a menarca, simbolizam o estado de plenitude - física (que inclui os atributos estéticos) e moral (relativa a qualidades e comportamentos) - da menina-moça, considerada pronta para constituir seu próprio 
grupo de substância. ${ }^{11}$ A elas é atribuído o termo kujämukukyry, que remete justamente à formosura das adolescentes, onde -kyry denomina algo brotando, desabrochando.

Os discursos masculinos sobre sexualidade aparecem como um locus privilegiado de expressão de rivalidades e tensóes entre famílias, grupos políticos ou mesmo na relaçáo com outras categorias de alteridade. $\mathrm{O}$ depoimento abaixo procura enfatizar o discurso de um rapaz de determinado grupo político que procura se diferenciar dos demais wanã (grupos políticos) por sua prática, ou seja, pela forma de abordagem e de consumação da iniciação sexual de uma menina-moça.

... hoje em dia nós somos diferentes dos outros wanã... eles principalmente pegam a menina, nem conversa, nem bate-papo... se ela não aceita nós não vamos pegar... se não aceita está certo, nem liga pra ela... só quando a mulher quer mesmo... tem que ir devagar, aí a menina entrega assim, normal... faz sanguinho... outro dia bateu papo de novo, volta de novo... náo precisa abrir na marra, eu não tenho vergonha de falar... tem que amolecer... ${ }^{12}$

Apesar da ênfase dada às diferenças no comportamento adotado por diferentes wanâ, na prática muitos fatores parecem contribuir para definir a performance dos rapazes na iniciaçáo de uma menina-moça. E a referência aos grupos políticos parece funcionar mais como uma estratégia de acusação do que um marcador diferencial de diferentes formas de agir. $\mathrm{Na}$ prática, jovens de um mesmo grupo político podem ter atitudes bastante distintas quanto à iniciação de uma menina-moça.

Por fim, a iniciação feminina é percebida tanto por mulheres quanto por homens de uma mesma maneira: "é wajäpi reko",13 "assim que é nossa cultura", "é saúde para a mulher". ${ }^{14} \mathrm{O}$ termo "saúde", nesse contexto, além de estar direcionado às profissionais de saúde que atuam na Terra Indígena, parece tentar traduzir a presença de todas as potencialidades e qualidades capazes de operar a passagem dessas meninas-moças para a vida adulta.

\section{Relações conjugais e extraconjugais}

Antes de abordar as relaçóes extraconjugais, apresento, ainda que concisamente, como são concebidas as relaçôes conjugais. O casamento resulta de um processo intenso de negociaçóes entre famílias. Em tempos passados, era bastante comum que esses arranjos fossem realizados pelos pais, enquanto os filhos eram ainda bastante pequenos. Atualmente muitos 
jovens escolhem seus próprios cônjuges, mas as negociaçóes de troca entre as famílias persistem.

Por "casar" (-wereko), subentende-se a constituição de um novo grupo de substância, forjado especialmente pela manutençáo de relaçóes sexuais constantes com o parceiro. ${ }^{15}$ Também implica no processo de acostumar-se (-jipokua), construído através do desempenhar de atividades cotidianas conjuntas, possibilitando uma intensa troca de fluidos corporais. A convivência, as relaçóes sexuais constantes e a fidelidade nos primeiros tempos do casamento são essenciais para consolidar o novo grupo de substância. $\mathrm{O}$ casamento diz respeito não somente à potencialidade de produzir, mas também de reproduzir um grupo de substância, a partir da elaboração dos filhos.

A regra preferencial é o casamento entre primos cruzados reais ou classificatórios, que se tratam mutuamente por emena (meu marido) e ererekwara (minha esposa). Esses termos, além de prescreverem a qualidade das relaçóes, implicam também na legitimidade de acesso sexual privilegiado, ainda que necessariamente discreto, entre as pessoas que os utilizam.

De acordo com Cabalzar (1997, p. 89), há categorias de parentesco com as quais os casamentos são expressamente proibidos:

\footnotetext{
Nossa "irmâ", nossa "mãe”, nossa "filha”, nossa "sogra", nossa "nora", nossa "neta". A gente não mexe com elas. Se chamar algumas delas de "esposa" [ererekwara], os outros vão dizer: "Por que você transa com ela? [Mano ojipiu tesipo peiko.] Se parente "outro" [outra "irmâ", "mãe", "filha”, "sogra”, "nora”, "neta”], então não tem problema.
}

Depois de efetivado um casamento, ocorre uma reclassificação da parentela a partir da aliança. Uma mulher vai tratar os irmáos de seu marido como emena e o marido irá designar as irmás de sua esposa como ererekwara. Esses termos possibilitam uma extensão tanto simbólica quanto concreta do casamento, materializada através dos acessos sexuais. Se em tempos passados a mistura entre grupos locais não era muito apreciada, atualmente a maioria dos casamentos ocorre fora do grupo local ou entre grupos locais que possuem interesse em se aliar politicamente.

Se por um lado as relações sexuais estão intrinsicamente relacionadas à concepção do que seja casamento, por outro não se resumem a essa instituição. As relações sexuais são concebidas também fora do casamento, mas de uma forma bastante distinta da que ocorre em nossa sociedade. As relaçóes extraconjugais são institucionalizadas porque reconhecidas e legitimadas socialmente, ainda que exijam discrição para sua realização e provoquem muito ciúme. 
É assim Wajãpi... difícil, não tem homem que namora só com mulher dele e mulher só com o marido dela...

Juntamente com a realização dos desejos, as relaçóes extraconjugais desempenham um papel extremamente importante no processo de concepção, no qual é necessário que uma mulher tenha muitas relações sexuais, afim de que o acúmulo de esperma possa formar, pouco a pouco, uma criança dentro de seu corpo. ${ }^{16}$ Desse processo cumulativo, náo participa somente o cônjuge, mas também os "maridos classificatórios" e outros homens com os quais a mulher tenha tido relaçóes sexuais no período da gravidez.

... para os Wajāpi é assim... se uma menina está grávida, outro rapaz pode transar, outro ainda se transar já é pai também... pai do menino... outro rapaz namora, é pai do menino também... pode ser quatro, dez rapaz... quem namorou já é pai também... depois faz resguardo escondido...

Todos aqueles que depositaram esperma no corpo da mulher e, portanto, ajudaram a fazer a criança são considerados pais, ainda que veladamente, mas o marido - que é seguramente um dos pais - assumirá a criança tratando de alimentá-la e partilhando suas substâncias. Portanto, as relações extraconjugais estão abarcadas em um princípio mais amplo que diz respeito à própria dimensão sociopolítica do grupo: a disseminação de substâncias, designada pelos Wajápi pelo termo janejeapyrerã ("nosso jeapyrerä"). Gallois (1993, p. 25) já apontara que jeapyrerã está relacionado a uma concepção genealógica "que permite percorrer as trilhas da dispersão ou da recuperação histórica dos subgrupos" wajápi. Por esse motivo, muitos Wajápi fazem alusão à descendência, ainda que não expressa publicamente, a partir da disseminação das próprias substâncias:

Meu jeapyrerã tem em todo lugar por onde eu namorei e ajudei a fazer filho.

O princípio de disseminação de substâncias sugere tanto um movimento no sentido de abrandamento das diferenças, por meio da afinização e descendência, quanto um movimento de predação, reativando espirais de vingança. As diferenças e perigos são representados fundamentalmente por outros grupos locais (amó kö), por aqueles categorizados como parceiros de troca (panare kô) ou pelos náo índios (karai kó). 
Os namoros nas aldeias ocorrem especialmente com os amó kó, pessoas de outros grupos locais que não o de pertença. Vale ressaltar que uma aldeia não corresponde a um grupo local, que geralmente está fragmentado em várias aldeias.

$\mathrm{Na}$ época de abertura das roças, os Wajãpi costumam peregrinar de caxiri em caxiri, para conversar, beber e namorar. Portanto, nem sempre é preciso sair da aldeia para namorar extraconjugalmente.

Quando minha mulher está aqui e vou pra outra aldeia, ela sabe que eu vou namorar lá e eu sei que ela, se tem kasiri, vai namorar aqui. Mas não fala um pro outro não. Mas se um fica sabendo, é obrigado, é uma troca; quando o homem fica sabendo que a mulher transou com outro, ele namora também. Mas não namora só quando um está longe, às vezes ou marido ou mulher dorme no kasiri, aí o outro namora, perto mesmo, no mesmo kasiri, na mesma aldeia.

As relações extraconjugais não devem ser explicitadas, mantendo-se discretas dentro de uma "ética de moderação wajãpi" ${ }^{17}$ Se os cônjuges supóem os namoros extraconjugais, a confirmação destes, através das redes de insinuaçôes, obriga-os necessariamente à retaliação ("se um fica sabendo é obrigado, é uma troca").

Quanto aos panare kó, parceiros de troca, são considerados belos, sedutores, atraentes e extremamente perigosos. A cidade ou mais especificamente a CASAI (Casa de Saúde Indígena) são os lugares onde ocorrem as relaçóes com os panare kó:

Mulher nova vem aqui na CASAI, aí acha bonito parente, aí quer namorar com ele, aí ele dorme perto dela... aí ela fala "vem namorar comigo"... até mulher mais velha quer namorar com Karipuna, Tiriyó, Apalai e Wayana.

Já os karai kõ (não índios) não são tão atraentes como os panare kó, e seus comportamentos variam de extremamente agressivos, ou seja, de inimigos $^{18}$ a parceiros de trocas. Com a intensificação do processo de assalariamento, muitos Wajápi que vão para a cidade acabam namorando mulheres karai kó, em geral prostitutas. Segundo os jovens wajãpi, as mulheres karai kó despertam curiosidade e interesse.

Mulher branca é diferente de Wajápi, porque tem vagina grande [qualidade valorizada pelos Wajápi], corpo lindo, bumbum grande... acha que é bonita karai kó, acha diferente. 
Mas, além disso, há diferenças também no jeito de namorar, que têm promovido mudanças, especialmente no comportamento dos jovens.

... mulher karai kó namora diferente de Wajăpi... índia namora calma, karai kó namora de outro jeito, agitado... aí gosta de namorar com karai kó... índia não faz nada.

As mulheres wajápi dizem que o homem karai kó dá mais prazer para elas, por isso hoje em dia está mudando o jeito de namorar... alguns beijam a mulher ou então fazem a transa mais demorada.

As relaçóes sexuais com os karai kó continuam ocupando uma posição estruturalmente ambígua nas teorias e práticas wajāpi: ora são incorporadas no registro da vingança, ora no sentido de afinização ("ela [prostituta] não sabe, mas ele [rapaz wajãpi] está fazendo o filho dela”).

Em síntese, as relações conjugais e extraconjugais são fundamentais porque são capazes de produzir afinidade e descendência, bem como de colocar em movimento, em novos termos, espirais de vingança e predação, possibilitando, pela via das substâncias, a construção de identidades wajápi.

\section{Considerações finais}

Procurei, neste artigo, a partir de dados etnográficos, evidenciar como a iniciação sexual feminina e também as relaçóes extraconjugais compóem um vasto universo de experimentaçóes, sustentadas em teorias wajápi acerca da sexualidade. Trata-se de elaboraçóes complexas, que náo podem ser dissociadas umas das outras e envolvem concepçóes de corpo, fluidos corporais, substâncias, relações de afinidade, predação, elaboração de sentimentos e experimentaçóes.

Se a iniciação sexual, em nossa sociedade, continua sendo um grande tabu que ocorre geralmente de forma velada e, em geral, produz pouco ou quase nenhum impacto em relação ao estatuto social da jovem, para os Wajápi a iniciação sexual vem permeada de carga significativa de efeitos. A iniciação é um marco fundamental da entrada das meninas no mundo dos adultos. Essa nova condição social anuncia que elas são capazes, por suas qualidades e conhecimentos, de produzir e reproduzir seus próprios grupos de substância. Esse movimento de produção e reprodução só é possível se mantida uma constância nas relaçóes sexuais, sejam elas conjugais ou extraconjugais.

Nos dias atuais, as iniciaçóes têm ocorrido na maior parte das vezes fora dos arranjos de casamentos, impossibilitando as mães das jovens de dis- 
penderem os cuidados necessários à sensibilização e aconselhamento dos futuros genros quanto às primeiras incursóes sexuais de suas filhas. Porém há de se ressaltar que a diminuição do controle social sobre esse processo aumenta a possibilidade das jovens terem a oportunidade de escolher os parceiros com os quais desejam ter sua primeira experiência sexual.

Quanto às relaçóes extraconjugais, vale apontar pelo menos dois aspectos que as distinguem da forma como estas são concebidas no(s) mundo(s) dos karai kó. O primeiro aspecto seria a questão da institucionalizaçáo destas relaçóes, essencial para pôr em movimento - juntamente com as relaçóes conjugais -, o princípio de disseminação de substâncias que os Wajápi denominam por jeapyrerã. Um segundo aspecto está relacionado à realização dos desejos. Se para os náo índios são os homens, em geral, que possuem legitimidade social para vivenciar as relaçôes extraconjugais, para os Wajāpi homens e mulheres não só podem como devem satisfazer seus desejos, desde que dentro dos parâmetros de discrição estabelecidos pelo grupo.

Por fim, o campo da sexualidade se mostrou um locus extremamente fértil para apreender de que forma as experimentaçóes e questionamentos wajāpi têm produzido incrementos e transformaçōes em suas próprias práticas, significados e teorias. O movimento para os Wajápi é essencial: como gostam de enfatizar, quem fica parado é jaboti!

\section{Notas}

1. Aproximaçôes à temática das DST junto aos Wajāpi do Amapari. Um estudo sobre malefícios, fluidos corporais e sexualidade, defendida no Departamento de Antropologia Social da USP (2005).

2. $\mathrm{Na}$ época em que desenvolvi minha pesquisa de mestrado, eram relativamente escassos os trabalhos em etnologia no Brasil dedicados à temática da sexualidade, com destaque para Gregor (1985), McCalum (1997), Camargo (1999) e Erickson (2000). Mais recentemente, tem-se Panet (2010) e Lea (2013).

3. São diversas as explicaçóes apresentadas pelos Wajãpi acerca dessa irresistibilidade: a beleza dos inimigos, a importância da disseminação de substâncias, a continuidade das guerras em outros termos, enquanto mecanismo para evitar agressóes etc.

4. Como dito anteriormente, os Wajāpi costumam utilizar a palavra "namorar" para designar "ter relaçôes sexuais". Atualmente os jovens, especialmente os que estão morando nas cidades, têm incrementado o namoro com outras práticas, como "ficar curtindo", "beijar" etc.

5. Vale apontar que a categoria gênero, como Heilborn (1999, p. 12) diz, é "fundante no modo como a experiência sexual é vivenciada pelos sujeitos, 
na medida em que as trajetórias masculinas e femininas são radicalmente distintas, não exatamente pelas diferenças estampadas em seus respectivos corpos, mas sobretudo em função da maneira como as expectativas e aspiraçôes em relação à experimentação sexual são marcadas".

6. Essas novas referências podem ser acessadas tanto em perfis dos jovens nas redes sociais ou mesmo em vídeos que são postados no YouTube. Os endereços a seguir são de vídeos de funks produzidos por um Wajāpi, MC KW, e que fazem apologia ao sexo: <https:/www.youtube.com/watch?v=17HmH1BZzbc>, acessado em 10/12/2015; <https://www.youtube.com/watch?v=hyJMqHNduMI\&feature=youtu.be $>$, acessado em 19/08/2015; <https://www.youtube.com/watch?v=nNKrtjkGaN8>, acessado em 19/08/2015.

7. Há uma série de reprimendas que os mais velhos fazem aos jovens. Destaco aqui algumas, como por exemplo: o uso de kamisa pirã (tanga vermelha) antes da "mudança do corpo" (ou seja, antes do aparecimento de pelos, seios, menstruação), a ingestáo de caxiri prematuramente (que provocaria um endurecimento dos ossos a partir das articulaçóes, causando uma má constituição dos corpos), a falta do sentimento de vergonha (extremamente valorizado para a constituição das pessoas e corpos) e a precocidade dos "namoros" (que influenciaria diretamente na falta de qualidades pessoais, em especial relacionados à caça e às atividades da roça).

8. Os caxiris são reuniôes em que se consomem grandes quantidades de bebidas fermentadas, em geral feitas de mandioca.

9. Esse receio aparece também no trabalho de Camargo sobre os Caxinauá: "Embora o sexo não seja um tabu no cotidiano dos Caxinauá, mocinhas ainda têm receios quanto à iniciação"(1999, p. 136).

10. Mais uma vez os Caxinauá protagonizam algo semelhante: "As ervas provocam, segundo os índios, o sentimento de 'desejo do esposo'. Terminados os banhos, o marido pode entáo encontrar sua esposa amansada e fazer sexo com ela. Não há mais medo, a menina não ficará mais assustada para ter relaçóes sexuais" (CAMARGO; 1999, p. 136).

11. Os seios crescidos (susupa) ou bem formados (susu ma'e) simbolizam a potencialidade de produzir leite, amamentar, alimentar através das próprias substâncias aqueles que consolidam o grupo de substância enquanto tal, ou seja, os descendentes. (Termos para os seios retirados de Cabalzar (1997, p. 76-77).)

12. É preciso salientar que a fala desse rapaz foi direcionada exclusivamente a mim, sem a presença de outros rapazes ou mulheres durante nossa conversa na aldeia.

13. A expressão wajāpi rekó é utilizada para designar o "modo de ser wajápi" delineado pela aprendizagem de modos de conhecer (modos de falar, can- 
tar, dançar, abrir roça, caçar, preparar os alimentos, buscar lenha, cuidar dos filhos, construir casas, fazer objetos úteis e enfeites etc.) e pela adoção de um vasto sistema de atitudes e regras de etiquetas que valoriza fundamentalmente o comportamento moderado.

14. Essa expressão é amplamente utilizada para fazer legitimar, especialmente perante aos não índios, os valores contidos nas formas de iniciação sexual das meninas e dos rapazes.

15. Cabalzar (1997, p. 102) transcreve a fala de um rapaz que não se considera efetivamente casado, pois não mantem relações sexuais constantes com a menina-moça: "Faz muito tempo que transei com ela... por isso não estou casado".

16. A concepção de que é preciso muitas relações sexuais para produzir uma criança encontra-se presente em muitos povos, como apontaram Gallois (1988), Viveiros de Castro (1986), Lagrou (1998), Lima (1998) etc. Porém, a originalidade aqui se deve a institucionalização das relaçôes extraconjugais nesse processo.

17. Ver Gallois (1988, p. 213-223).

18. Gallois, em 1988, apontara que a "violência sexual dos brasileiros, [é] temida [...] pelas mulheres do Amapari, que comparam o órgão sexual dos brancos a uma arma; aliás, as relações sexuais com estrangeiros são concebidas como um retalhamento interno, uma vez que os karai kó são tidos como porosu'u (= aqueles que nos mordem)" (1988, p. 345). Essa representação da violência é atualizada através de depoimentos de namoros dos Wajápi com os karai kó. Se no passado a agressividade sexual era associada especialmente aos garimpeiros, atualmente os agiotas, que emprestam dinheiro a juros altíssimos para os Wajãpi, têm assumido esse lugar.

\section{Referências bibliográficas}

\section{CABALZAR, Flora Dias. Trocas matrimoniais e relaçóes de qualidade entre os} Waiāpi do Amapá. São Paulo, 1997. Dissertação (Mestrado em Antropologia Social) - Faculdade de Filosofia Letras e Ciências Humanas, Universidade de São Paulo.

CAMARGO, Eliane. Alimentando o corpo. O que dizem os Caxinauá sobre a função nutriz do sexo. Sexta-Feira. Antropologia, artes e humanidades, v. 4, p. 130-137. 1999.

GALLOIS, Dominique Tilkin. Mairi revisitada: a reintegração da fortaleza de Macapá na tradição oral dos Waiãpi. São Paulo: NHII-USP/FAPESP, 1993. . O movimento na cosmologia waiäpi: criação, expansão e transformação do universo. São Paulo, 1988. Tese (Doutorado em Antropologia Social) - Faculdade de Filosofia Letras e Ciências Humanas, Universidade de São Paulo. 
HEILBORN, Maria Luiza. Sexualidade: o olhar das ciências sociais. Rio de Janeiro: Jorge Zahar Editor, 1999.

LAGROU, Elsje. Caminhos, duplos e corpos. Uma abordagem perspectiva da identidade e alteridade entre os Kaxinawa. São Paulo, 1998. Tese (Doutorado em Antropologia Social) - Faculdade de Filosofia Letras e Ciências Humanas, Universidade de São Paulo.

ROSALEN, Juliana. Aproximaçóes à temática das DST junto aos Wajāpi do Amapari. Um estudo sobre malefícios, fluidos corporais e sexualidade. São Paulo, 2005. Dissertação (Mestrado em Antropologia Social) - Faculdade de Filosofia Letras e Ciências Humanas, Universidade de São Paulo.

autora Juliana Rosalen

É doutoranda no Programa de Pós-Graduação em Antropologia Social da Universidade de São Paulo.

Recebido em 10/12/2015 Aceito para publicação em 11/02/2016 